\title{
The mechanical properties of the Microcystis gas vesicle
}

\author{
A. E. WALSBY \\ Department of Botany, University of Bristol, Woodland Road, Bristol BS8 IUG, UK
}

(Received 22 April 1991; accepted 25 June 1991)

\begin{abstract}
Gas vesicles isolated from the cyanobacterium Microcystis sp. retained their high stability and critical pressure on storage and could be held under a sustained pressure of $0.5 \mathrm{MPa}$ without collapse. Application and release of pressures up to $0.5 \mathrm{MPa}$ gave reversible changes in volume that indicated an elastic compressibility of $0.0087 \mathrm{MPa}^{-1}$, which was linear with pressure. The elastic bulk modulus of the Microcystis gas vesicle was $115 \mathrm{MPa}$. The average yield pressure of the gas vesicles, $4 \cdot 3 \mathrm{MPa}$, was determined by infiltrating them with gas at high pressure and then releasing the pressure so that they exploded. From these two measurements the proteinaceous wall of the gas vesicle was calculated to have a Young's modulus of $3.8 \mathrm{GPa}$ and a yield stress of $78 \mathrm{MPa}$. These values correspond closely to those of nylon, which has a similar secondary structure to that of the gas vesicle protein. The critical collapse pressure of the Microcystis gas vesicle, $0.8 \mathrm{MPa}$, is substantially higher than the theoretical buckling pressure, $0.2 \mathrm{MPa}$, for an unstiffened homogeneous cylinder of similar relative dimensions. The stiffening of the gas vesicle may be provided by its outer layer of GVPc, since the removal of this protein decreases the critical pressure to $0.23 \mathrm{MPa}$. The volumetric compressibility of the gas vesicle generates a small reversible change in turbidity (0.008 $\left.\mathrm{MPa}^{-1}\right)$. Spectrophotometric measurements showed that a gas vesicle suspension containing $1 \mu \mathrm{ml}^{-1}$ of gas gives a pressure-sensitive optical density of $2.03 \mathrm{~cm}^{-1}$ at a wavelength of $500 \mathrm{~nm}$.
\end{abstract}

\section{Introduction}

The gas vesicles of cyanobacteria and other aquatic prokaryotes are hollow structures that provide buoyancy. The wall of the gas vesicle is made of protein molecules stacked in ribs arranged in the form of a cylindrical tube closed at each end by a hollow cone. The structure is rigid and will withstand considerable pressures before collapsing to a flattened envelope (see Walsby, 1972, 1989, for reviews).

In nature, gas vesicles encounter hydrostatic pressures generated principally by the overlying water column and the osmotically generated cell turgor pressure. These pressures range from as little as $0.01 \mathrm{MPa}(0 \cdot 1 \mathrm{bar})$ inside halophilic bacteria inhabiting shallow brine pools, to more than $2 \mathrm{MPa}$ (20 bar) in cyanobacteria of the deep oceans (Walsby, 1971, 1978). There has been natural selection for gas vesicles of different strength in bacteria that encounter different pressures; the strongest gas vesicles have the narrowest diameter and provide less buoyancy. Where high pressures are not encountered, weaker and wider gas vesicles are found (Walsby, 1972; Hayes \& Walsby, 1986; Walsby \& Bleything, 1988); they provide buoyancy with greater efficiency (Walsby, 1987).
In an attempt to understand what determines the pressure at which a gas vesicle collapses, the elastic properties of the gas vesicle have been investigated (Walsby, 1982). Measurements were made of the reversible, elastic compressibility of gas vesicles isolated from the cyanobacterium Anabaena flos-aquae. Application of a pressure $P=0.1 \mathrm{MPa}$, considerably less than the critical collapse pressure, caused a relative volume reduction $(\mathrm{d} V / V)$ of only 0.0155 . From this value, and measurements of the cylinder radius and wall thickness, an estimate of the average Young's modulus of the gas vesicle wall protein was obtained, $Y=2.8 \mathrm{GPa}$. A general theory for buckling of thin-walled hollow structures (DeHart, 1969) indicates that a cylinder with the relative dimensions and properties of the Anabaena gas vesicle would collapse at a pressure of only $0.06 \mathrm{MPa}$, if it were of homogeneous construction. The observation that the critical collapse pressure $\left(p_{c}\right)$ of the Anabaena gas vesicle was about 10 -fold higher (0.6 MPa) suggested that the elements in the gas vesicle wall were arranged in such a way as to stiffen the structure and so postpone buckling. It was suggested that the arrangement of the gas vesicle protein into ribs might provide ring-stiffening support (Walsby, 1982) and that the stresses in the gas vesicle wall would be equalized in the hydrogen bonds 
between the $\beta$-chains in the protein, which are orientated at a special angle to the principal axis of the cylinder (Walsby, 1987).

In a thin-walled cylindrical structure, like the gas vesicle, that collapses by instability failure (DeHart, 1969) a measure of its mechanical efficiency can be obtained by comparing the average critical stress $\left(s_{\mathrm{c}}\right)$ in the wall, as the structure approaches its critical pressure $\left(p_{c}\right)$, with the yield stress $\left(s_{y}\right)$ at which the wall material fails. In instability failure the cylinder goes out-of-round so that the stresses are unevenly distributed and buckling results. The only way to determine the yield stress in such a structure is by measuring the pressure required to explode it, as buckling does not occur in a cylinder distended by internal pressure.

The gas vesicle is highly permeable to gases and the gas pressure inside it can be raised by slowly infiltrating the suspending medium with gas (Walsby, 1969). The gas vesicle will not collapse as long as the pressure difference between the gas above the suspension and that in the structure does not exceed $p_{\mathrm{c}}$ during the pressure rise; with this precaution gas vesicles can be loaded with gas at $5 \mathrm{MPa}$ or more (Walsby, 1984).

I describe below experiments in which the gas pressures above such supersaturated suspensions were suddenly released, causing gas vesicles to explode. By finding the pressure required to do this, the yield pressure $\left(p_{y}\right)$ of the gas vesicle could be determined. The experiments are similar to those performed on suspensions of bacteria by Hemmingsen \& Hemmingsen (1980). They found that cells containing gas vesicles were blown apart by gas bubbles that nucleated from the expanding vesicle gas. In a detailed quantitative analysis of their experiments it was concluded that these bubbles would have arisen from exploded gas vesicles (Walsby, 1989) though there was no direct evidence of this.

Measurements of the critical pressure and yield pressure described below were made on gas vesicles isolated from the cyanobacterium Microcystis sp. They are similar in structure to those of Anabaena but they are somewhat narrower and, consequently, have a higher critical pressure (Walsby \& Bleything, 1988). They also remain more stable when isolated from the cells (Walsby \& Hayes, 1988) and do not show the anomalous instability, when held under pressure, that has been encountered with gas vesicles isolated from Anabaena (Walsby, 1980). This has permitted more accurate measurements to be made of their elastic compressibility and other properties.

The mechanical principles of the Microcystis gas vesicles should be generally applicable to those of other cyanobacteria, as they have a similar molecular structure. The main component, GVPa, is a highly conserved, small, hydrophobic protein (Tandeau de Marsac et al.,
1985; Walker et al., 1984; Hayes et al., 1986), which forms the ribs of the structure (Walsby \& Hayes, 1988). The gas vesicles of Anabaena and Microcystis (Hayes et $a l ., 1988$ ) and certain other cyanobacteria (see Damerval et al., 1987, 1989) also contain a second, larger, hydrophilic protein, GVPc, which occurs on the outer surface. Gas vesicles are markedly weakened when GVPc is removed (Walsby \& Hayes, 1988), but they regain their strength when this protein rebinds onto the structure, perhaps because it holds the ribs together (P. K. Hayes, B. Buchholz \& A. E. Walsby, unpublished).

\section{Methods}

Gas vesicle isolation. The cyanobacterium Microcystis $\mathrm{sp}$. strain BC 84/1 was grown in medium BG 11 of Rippka et al. (1979). Gas vesicles were isolated from cells lysed with lysozyme and were purified with the methods described by Walsby (1974) and Hayes (1988). They were stored at $5{ }^{\circ} \mathrm{C}$ in a solution of $6 \mathrm{~mm}-\mathrm{NH}_{4} \mathrm{HCO}_{3}$ and $5 \mathrm{~mm}-\mathrm{NaCN}$.

Critical collapse pressures. The critical pressure distribution of the gas vesicles was determined by turbidity measurements (Walsby, 1980) with a modification of the pressure nephelometer of Walsby (1973) fitted with a Kistler 4041 A50 pressure transducer connected to a fourplace digital display sensitive to $0.5 \mathrm{kPa}(5 \mathrm{mbar})$. The transducer was calibrated against a mercury column and a pressure balance. The output of the nephelometer photocell was recorded on another four place digital meter. The percentage of gas vesicles collapsed at a given pressure was calculated as $100\left(T-T_{\mathrm{b}}\right) /\left(T-T_{\mathrm{c}}\right)$, where $T$ is the initial turbidity of the suspension, $T_{\mathrm{b}}$ is the turbidity remaining after applying the pressure, and $T_{\mathrm{c}}$ is the turbidity remaining after all the gas vesicles were collapsed (Walsby, 1973). The turbidity was measured after the pressure at each step had been held for about $12 \mathrm{~s}$. The statistical methods of Walsby \& Bleything (1988) were used to calculate the median $p_{\mathrm{c}}$, the mean $p_{\mathrm{c}}$ and the standard deviation of the critical pressure distribution. All the pressures given are gauge pressures (in excess of the ambient pressure). Critical pressures were determined with suspensions of gas vesicles that had been equilibrated with air at the ambient pressure; the pressure of the vesicle gas is then identical to the ambient pressure, because the gas vesicles are highly permeable to gas (Walsby, 1984).

Compressibility. Measurements of the compressibility and gas content of gas vesicle suspensions were made by the methods described by Walsby (1982). A compression tube with an open-ended capillary was filled with the gas vesicle suspension and thermally equilibrated in a pressure tube with a thermostatted water jacket (Oliver \& Walsby, 1988). Pressure was transmitted to the gas vesicle suspension via the open capillary. The resulting reduction in volume of the gas vesicles was indicated by the change in position of the meniscus in the capillary, after due allowance was made for changes in volume of the suspending water and the capacity of the glass tube. The volume of gas-vesicle gas in a suspension was determined from the irreversible change in volume after applying and the releasing a pressure $(1.3 \mathrm{MPa})$ that collapsed all of the gas vesicles.

Yield pressure of the gas vesicles. Suspensions of gas vesicles were equilibrated with nitrogen or helium gas at high pressure in a stainless steel tube attached to a gas-handling system constructed from $3 \mathrm{~mm}$ diameter, $1 \mathrm{~mm}$ bore Teflon tubing connected with Swagelok pressure connectors to Whitey miniature forged-body needle valves and shut-off 


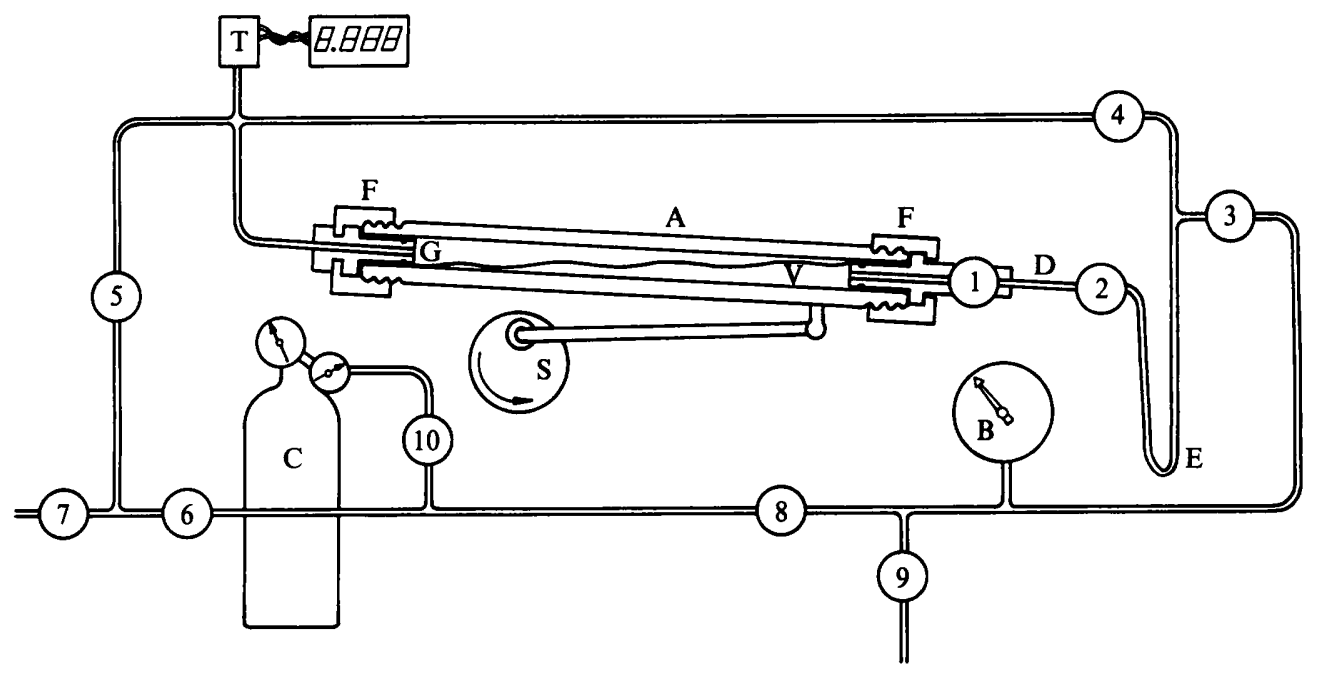

Fig. 1. Schematic diagram of the apparatus used to equilibrate gas vesicles (V), in aqueous suspension, with gas (G) at high pressure, and then subject them to rapid decompression, causing them to explode: A, stainless steel pressure tube; B Bourdon-tube pressure gauge; C, cylinder of compressed gas; D, E, sections of microbore tubing used for D, decompression of the gas vesicles, and E, expansion of the decompressed suspension; F, pressure connector; S, reciprocal shaker; $T$, pressure transducer with $10 \mathrm{MPa}$ digital display; $1-10$, shut-off valves or needle valves $(6,8,9)$ used to regulate gas flow.

valves (Fig. 1). The section of the apparatus between valves 3 and 5 was mounted on a shaker with a $35 \mathrm{~mm}$ stroke, oscillating at $1 \mathrm{~Hz}$. The apparatus was operated as follows.

(1) With valve 1 closed, $5 \mathrm{ml}$ of gas vesicle suspension (V) was placed in tube $A$, the pressure connector $F$ was inserted and the shaker was started. (2) With valves $2,3,4$ and 5 open, and 6, 7, 8, 9 and 10 closed, the pressure in the regulator of gas cylinder $\mathrm{C}$ was raised to $5 \mathrm{MPa}$ or more. (3) Valve 10 was then opened. (4) By adjusting inlet valve 6 the gas pressure in tube $E$ and the rest of the system was raised at a rate not exceeding $0.4 \mathrm{MPa} \mathrm{h} \mathrm{h}^{-1}$, monitored on the output of the pressure transducer T. (5) When the final pressure was reached, valve 6 was closed and the suspension was equilibrated for a further $30 \mathrm{~min}$. A sample of the suspension was removed from tube $A$ for explosion as follows. (6) Tube $A$ was tilted so that the suspension covered the opening to valve 1. (7) Valve 1 was opened. (8) Valves 3 and 4 were closed. (9) Valve 9 was opened briefly, reducing the pressure on gauge $B$ by about $0.02 \mathrm{MPa}(0.2 \mathrm{bar})$, and then closed. (10) Valve 3 was opened slightly, causing $40 \mu \mathrm{l}$ of suspension $V$ to seep through valve 1 , filling the tubing $D$, and then valve 3 was closed. (11) Valve 2 , and then valve 1 , were both closed, and the following two steps were performed in quick succession. (12) Valves 3 and 9 were opened fully so that the gas pressure dropped completely. (13) Valve 2 was opened rapidly so that the pressure was released on the gas vesicles. When the pressure drop was sufficient the gas vesicles exploded. The suspension outgassed, expanding into the tubing $E$ between valves 2 and 3. (14) The compression fitting holding the tubing to valve 1 was unscrewed and the tubing end placed in an Eppendorf sample tube. (15) Outlet valve 9 was closed and by adjusting valve 8 the pressure was raised slightly to blow the 'exploded' sample into the sample tube. (16) The sample tube was removed and valve 8 was opened fully, to blast out any remaining drops of suspension; it was then closed. (17) The tubing was reconnected to valve 1. (18) Inlet valve 8 was operated to raise the gas pressure on gauge B to the same pressure as shown on transducer T. (19) Valve 4 was opened and the shaker restarted. (20) Valve 9 was operated to reduce the pressure by $0.5 \mathrm{MPa}$. The suspension in tube $\mathrm{A}$ outgassed until it was in equilibrium with the new pressure. (21) The cycle from step (6) to (21) was then repeated. (22) Finally, the pressure was slowly reduced to the ambient pressure and a final sample of suspension $\mathrm{V}$ was taken. The relative gas vesicle content of each of the samples was then determined by pressure nephelometry.

\section{Results}

\section{Critical pressure distribution of the gas vesicles}

Gas vesicles in cells of Microcystis sp., suspended in $0.5 \mathrm{M}$-sucrose solution to remove turgor pressure, had the critical pressure distribution shown in Fig. 2, curve A, with a median $p_{\mathrm{c}}$ of $0.780 \mathrm{MPa}$, a mean $p_{\mathrm{c}}$ of $0.787 \mathrm{MPa}$ and a standard deviation of $0 \cdot 140 \mathrm{MPa}$, similar to the values obtained by Walsby \& Bleything (1988). Gas vesicles were isolated and purified from the cell suspension. Eleven days after the start of the purification procedure they were concentrated into $2.3 \mathrm{ml}$ of suspension; a sample diluted 540 -fold in $5 \mathrm{~mm}-\mathrm{K}_{2} \mathrm{HPO}_{4}$ showed a critical pressure distribution (Fig. 2, curve B) with a median $p_{\mathrm{c}}$ of $0.890 \mathrm{MPa}$, a mean $p_{\mathrm{c}}$ of $0.867 \mathrm{MPa}$ and a standard deviation of $0.136 \mathrm{MPa}$. The turbidity readings were virtually steady after the $12 \mathrm{~s}$ applications of pressure at each step (but see below).

\section{Stability of isolated gas vesicles during storage}

The gas vesicle suspensions stored at $5^{\circ} \mathrm{C}$ remained intact over long time periods. Gas vesicles isolated from Anabaena flos-aquae appeared essentially unchanged in 10 years of storage, but they were mechanically much 


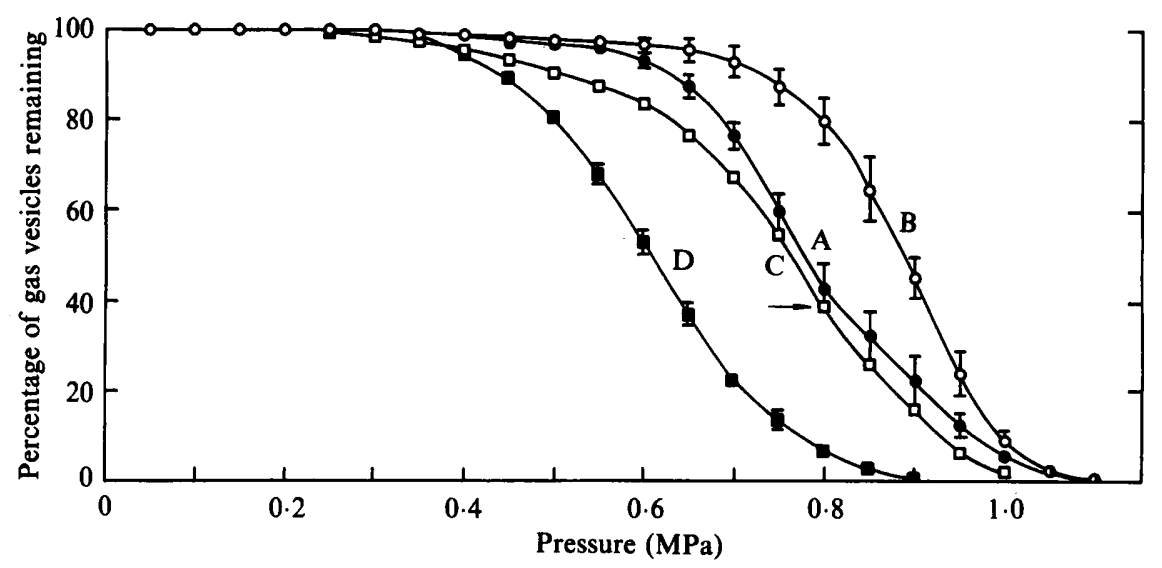

Fig. 2. Critical pressure distributions, determined by pressure nephelometry, of Microcystis gas vesicles: A, gas vesicles inside cells suspended in $0.5 \mathrm{M}$-sucrose (means and standard deviations of five measurements); B, suspension of purified gas vesicles, isolated from the cells used in measurement of bulk elastic modulus (means of three measurements); $C$, the same suspension after storage for 4 weeks, used to investigate stability under a sustained pressure of $0.8 \mathrm{MPa}$ (arrow) initially causing $61 \%$ gas vesicle collapse; $\mathrm{D}$, isolated gas vesicles stored at $5^{\circ} \mathrm{C}$ for over 2 years (means of four measurements).

weaker and collapsed on application of $<0 \cdot 2 \mathrm{MPa}$. The "Microcystis gas vesicles also became weaker during storage: the median critical pressure decreased from $0.89 \mathrm{MPa}$ to $0.80 \mathrm{MPa}$ after 4 weeks and, in another sample, to $0.61 \mathrm{MPa}$ after 2.4 years (Fig. 2, curve D). Most of the following experiments were performed on samples within 5 weeks of their preparation.

\section{Stability of isolated gas vesicles under sustained pressure}

In a sample of the original suspension left under pressure of $0.50 \mathrm{MPa}$ for $12 \mathrm{~s}$, the turbidity change indicated that $2.4 \%$ of the gas vesicles collapsed. Another sample of the same suspension left for over $20 \mathrm{~min}$ at the same pressure lost less then $3 \%$ of its gas vesicles. This indicated that the critical pressure was virtually independent of the exposure time. A more sensitive test of this was made (with the same preparation after 4 weeks' storage) by applying a pressure in the region of the steepest gradient on the critical pressure distribution (Fig. 2, curve C). The suspension was subjected to a pressure raised from 0 to $0.80 \mathrm{MPa}$ in $6 \mathrm{~s}$, and then held without change for $5 \mathrm{~min}$ while the turbidity change was recorded at frequent intervals (see Fig. 3). Immediately the initial pressure rise had stabilized (i.e. at $6 \mathrm{~s}$ ) the turbidity change indicated that $60.6 \%$ of the gas vesicles had collapsed. After a further $12 \mathrm{~s}$, the time interval routinely used between pressure increments, the percentage collapsed reached $61.6 \%$ and the value stabilized at $64.4 \%$ after 3.5 min (see Fig. 3).

\section{Elastic compressibility of the gas vesicle suspension}

A sample of the original (undiluted) suspension, containing approximately $60 \mu \mathrm{ml}^{-1}$ of gas vesicle gas, was

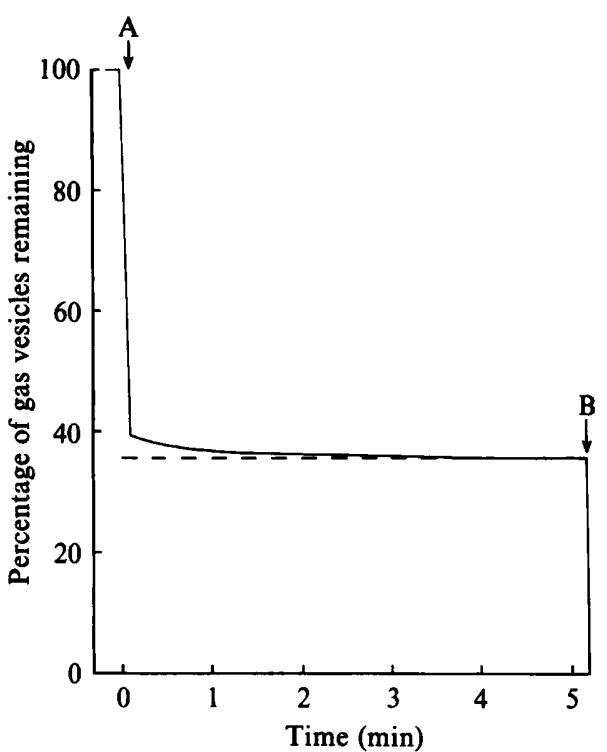

Fig. 3. Collapse of gas vesicles, indicated by the turbidity change, with time after applying a pressure at $A$ of $0.80 \mathrm{MPa}$; the broken line indicates the final percentage of gas vesicles collapsed; at $\mathrm{B}$ the pressure was raised to $1.45 \mathrm{MPa}$.

exposed to a hydrostatic pressure of $0.55 \mathrm{MPa}$ for $20 \mathrm{~min}$ to ensure that in subsequent repeated applications of $0.50 \mathrm{MPa}$ no further gas vesicles would collapse and that the only volumetric change that occurred would be due to elastic compressibility. Analysis of the collapse-pressure curve (Fig. 2, curve B) above $0.55 \mathrm{MPa}$ indicates that the critical pressure distribution of the gas vesicles remaining would have had a mean $p_{\mathrm{c}}$ of $0.882 \mathrm{MPa}$ and standard deviation of $0.098 \mathrm{MPa}$. 


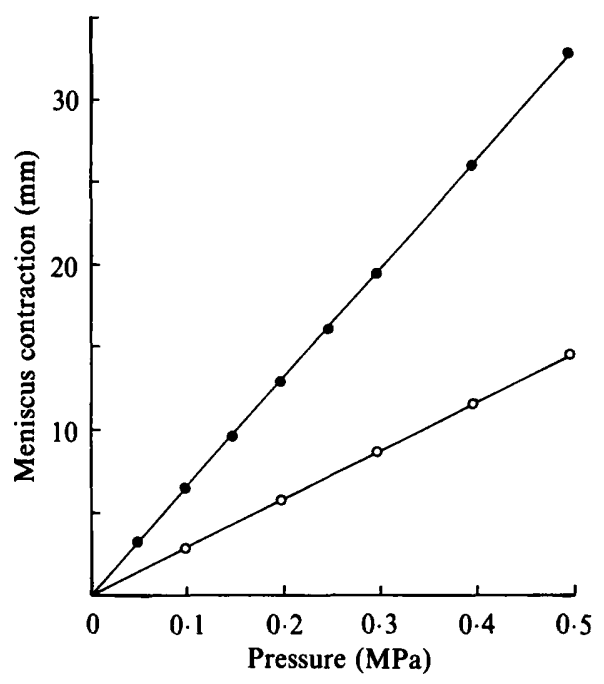

Fig. 4. Reversible changes in the position of the meniscus in the capillary of a compression tube containing $2155 \mu$ l of water $(O)$ or the same volume of a Microcystis gas vesicle suspension containing $124 \mu \mathrm{l}$ of gas space (O). The points at 0.1 MPa intervals are means of three or four measurements; the $95 \%$ confidence limits do not extend beyond the symbols.

A compression tube of capacity $2158 \mu$ l was filled with this suspension and equilibrated at $20^{\circ} \mathrm{C}$. The meniscus in the capillary of the tube stabilized at $95 \mathrm{~mm}$ from the open end, indicating that the volume of the suspension was $2155 \mu 1$. The pressure in the pressure tube was raised in steps of $0.05 \mathrm{MPa}$ to a final value of $0.25 \mathrm{MPa}$, or steps of $0.10 \mathrm{MPa}$ to a final value of $0.50 \mathrm{MPa}$, and then released. The position of the meniscus was noted at each step (Fig. 4) before proceeding to the next. The procedure was repeated several times. There was no significant change in the compressibility during the measurements; application of $0.40 \mathrm{MPa}$ gave a change in meniscus position of $25.89 \mathrm{~mm}$ at the start and $25.90 \mathrm{~mm}$ at the end of the series of readings, which showed that no gas vesicles were collapsed during the repeated compressions. The results (Fig. 4) showed that there was a linear change in meniscus position $\left(M_{\mathrm{s}}\right)$ with pressure $(P)$, described by the regression equation $M_{\mathrm{s}}=(-0.16+$ $66.12 \mathrm{P} / \mathrm{MPa}) \mathrm{mm}$, with a correlation coefficient of $r=$ 0.9999 for $n=28$ measurements. As a $1 \mathrm{~mm}$ change is equivalent to a volume decrease of $0.0314 \mu \mathrm{l}$, the results indicate an overall volume change of $\mathrm{d} V_{\mathrm{t}}=-2.077 \mu \mathrm{l}$ $\mathrm{MPa}^{-1}$ for the $2155 \mu \mathrm{l}$ of suspension in the compression tube. The overall contraction is made up of volume changes resulting from compression of the gas vesicles $\left(\mathrm{d} V_{\mathrm{g}}\right)$, the suspending water $\left(\mathrm{d} V_{\mathrm{w}}\right)$ and, in a counteracting manner, the compression tube $\left(\mathrm{d} V_{\mathrm{i}}\right)$ such that

$$
\mathrm{d} V_{\mathrm{t}}=\mathrm{d} V_{\mathrm{g}}+\mathrm{d} V_{\mathrm{w}}-\mathrm{d} V_{\mathrm{i}}
$$

(Walsby 1982). The values of the last two terms were determined by making similar measurements with the tube filled with water. The results (Fig. 4) again indicated a linear change in meniscus position with pressure, described by the regression equation $\boldsymbol{M}_{\mathrm{w}}=$ $(-0.07+29.27 \mathrm{P} / \mathrm{MPa}) \mathrm{mm}$, with a correlation coefficient of $r=0.9998$ for $n=8$ measurements. This indicated an apparent volume change of $\mathrm{d} V_{1}^{\prime}=$ $-0.920 \mu \mathrm{MPa}^{-1}$ for the $2155 \mu \mathrm{l}$ of water in the compression tube.

When the compression tube is subjected to pressure $P$ (equal on the inside and outside) its capacity $\left(V_{\mathrm{i}}\right)$ also undergoes a relative contraction that is given by

$$
\mathrm{d} V_{\mathrm{i}} / V_{\mathrm{i}}=-P / K
$$

where $K$ is the bulk elastic modulus of glass, $4.6 \times$ $10^{4} \mathrm{MPa}$. The volume change expected for the tube of $V_{\mathrm{i}}$ $=2155 \mu l$ is therefore $\mathrm{d} V_{\mathrm{i}}=-0.047 \mu \mathrm{MPa}^{-1}$.

Since this tube contraction has a counteracting effect on the movement of the water in the capillary, the actual volume change of the water is given by

$$
\mathrm{d} V_{\mathrm{w}}{ }^{\prime}=\mathrm{d} V_{\mathrm{t}}^{\prime}+\mathrm{d} V_{\mathrm{i}}
$$

and hence the total volume change of the water was $-0.967 \mu \mathrm{l}$. The compressibility of water, $-\mathrm{d} V_{\mathrm{w}}{ }^{\prime} / V_{\mathrm{i}} P$, indicated by these measurements was $(0.967 \mu 1 / 2155 \mu \mathrm{l})$ $\mathrm{MPa}^{-1}=4.49 \times 10^{-4} \mathrm{MPa}^{-1}$, which is within $1.6 \%$ of the published value, $4.56 \times 10^{-4} \mathrm{MPa}^{-1}$ (Hodgman, 1963).

\section{The elastic modulus of the Microcystis gas vesicle}

The compression tube was emptied of the gas vesicle suspension, which was diluted 98.94 -fold with water. The compession tube was then refilled with samples of diluted suspension and the change in the meniscus position was measured after applying, and the releasing, a pressure of 1.3 MPa. Triplicate determinations showed an irreversible contraction of $39.89 \pm 0.16 \mathrm{~mm}$, indicating the collapse of $1.253 \mu$ l of gas vesicle gas space. The gas volume in the $2155 \mu 1$ of the original undiluted suspension was therefore $124 \mu$ l.

According to the measurements of Walsby \& Bleything (1988) the gas occupies 0.885 of the total volume of the gas vesicle in this strain of Microcystis. The total volume of gas vesicles in the suspension was therefore $V_{g}$ $=140 \mu \mathrm{l}$ and the remaining volume occupied by water was $2015 \mu \mathrm{l}$. The expected volume change of this water would therefore have been $\mathrm{d} V_{\mathrm{w}}=-0.967 \mu \mathrm{MPa}^{-1} \times$ $2015 / 2155=-0.904 \mu 1 \mathrm{MPa}^{-1}$. Substituting the values for $\mathrm{d} V_{\mathrm{t}}, \mathrm{d} V_{\mathrm{w}}$ and $\mathrm{d} V_{\mathrm{i}}$ in equation (1) and rearranging gives $\mathrm{d} V_{\mathrm{g}}=(-2.077+0.904-0.047) \mu \mathrm{MPa}^{-1}=$ $-1.220 \mu \mathrm{l} \mathrm{MPa}{ }^{-1}$. Dividing by the volume of the gas vesicle gas space in the compression tube gives the compressibility of the gas vesicle as $\mathrm{d} V_{\mathrm{g}} / V_{\mathrm{g}}=$ 


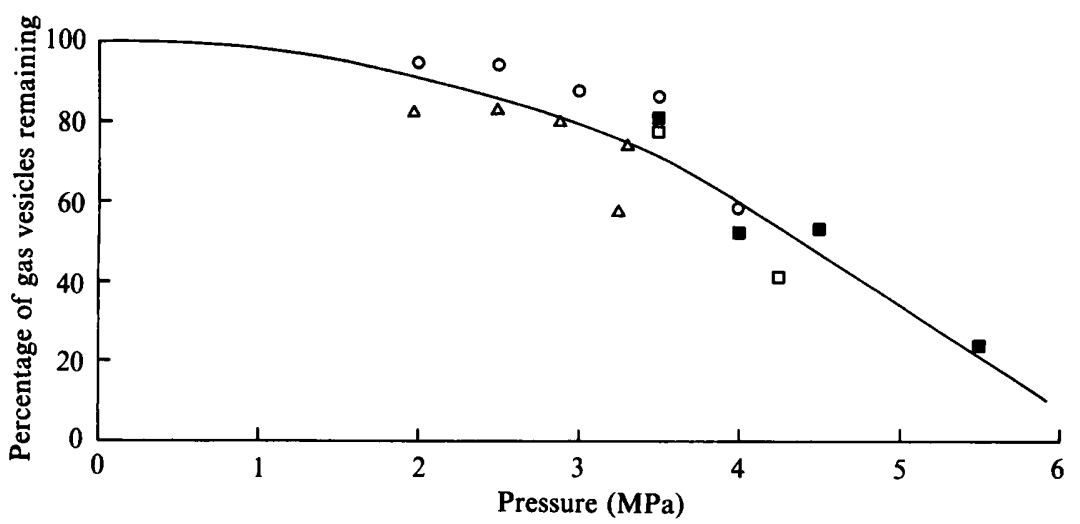

Fig. 5. The proportion of gas vesicles surviving rapid decompression after equilibration with gas at the pressure indicated. The different symbols indicate different experimental runs, using helium $(\square)$ or nitrogen $(O, \square, \triangle)$ as the equilibrating gas.

$-0.00871 \mathrm{MPa}^{-1}$. From this we can calculate the elastic bulk modulus of the gas vesicle as

$$
K_{\mathrm{a}}=-V_{\mathrm{g}} P / \mathrm{d} V_{\mathrm{g}}
$$

Hence, putting $P=1 \mathrm{MPa}, K_{\mathrm{a}}=115 \mathrm{MPa}$.

Elastic changes in gas vesicle volume detected by turbidity changes

The elastic compression of gas vesicles is known to cause a small reversible change in turbidity (Walsby, 1971). An attempt was made to measure this change and relate it to the volumetric change. The critical pressure distribution of a suspension, determined by pressure nephelometry, had a mean of $0.787 \mathrm{MPa}$ and standard deviation of $0.143 \mathrm{MPa}$. The initial turbidity reading given by the suspension was amplified to give nearly the maximum reading on the photometer of the nephelometer; the overall turbidity change on collapsing all the gas vesicles was 1785 units. During the sequence of pressure rises the $0.55 \mathrm{MPa}$ step was held on for $2 \mathrm{~min}$ and then released. The turbidity decreased by 116 units below the initial value, indicating $6.3 \%$ gas vesicle collapse. The $93.7 \%$ of gas vesicles remaining were exposed to repeated application, followed by release, of pressures from 0.1 to $0.5 \mathrm{MPa}$, resulting in reversible turbidity decreases of 1 to 6 units on the nephelometer. A regression analysis of the turbidity change $(\mathrm{d} T)$ and pressure $(P)$ gave $T=$ $(-0.6+13 \cdot 1 \mathrm{P} / \mathrm{MPa})$ units, with a correlation coefficient of $r=0.90$, on $n=18$ measurements. The relative turbidity change was therefore $13 \cdot 1 / 1669 \mathrm{MPa}^{-1}$, giving $\mathrm{d} T / T=0.0078$.

This reversible change is of the same order as the relative change in gas volume, $\mathrm{d} V / V=0.0098$, which generates the turbidity change. These turbidity changes are near the limit of detection and it cannot be concluded that the difference between the two measurements is significant. The reversible turbidity change caused by the compressibility of intact gas vesicles will generate a small error in the estimate by nephelometry of the percentage of gas vesicles collapsed by a given pressure. At the median collapse pressure of $0.8 \mathrm{MPa}$, for example, the percentage of gas vesicles remaining would be underestimated by $50 \% \times 0.8 \mathrm{MPa} \times 0.0078=0.3 \%$.

\section{Relation between gas vesicle volume and optical density}

Changes in turbidity provide the most sensitive method of detecting gas vesicles and measuring the relative changes in gas vesicle content, but it is difficult to standardize nephelometric measurements. However, the turbidity of gas vesicle suspensions generates an optical density (apparent light absorbance) that is reproducible and can be used in standardizing the concentration of the suspensions.

Six replicate measurements of gas volume were made on a gas vesicle suspension using $2.4 \mathrm{ml}$ capacity compression tubes. The suspension contained $0.5606 \pm$ $0.0098 \mu \mathrm{l} \mathrm{ml} \mathrm{m}^{-1}$ of gas. The suspension was diluted fivefold and eight measurements were made of the optical density at $500 \mathrm{~nm}$, before and after collapsing the gas vesicles with a pressure of $1.4 \mathrm{MPa}$. The mean pressure-sensitive optical density (PSOD) of the original undiluted suspension was $1.135 \pm 0.016 \mathrm{~cm}^{-1}$, and hence a PSOD of $1 \mathrm{~cm}^{-1}$ indicates a gas vesicle gas concentration of $0.494 \mu \mathrm{l} \mathrm{ml}^{-1}$. In the Microcystis gas vesicle the average ratio of gas volume to wall (protein) mass is $5.84 \mu \mathrm{mg}^{-1}$ (Walsby \& Bleything, 1988); a PSOD at $500 \mathrm{~nm}$ of $1 \mathrm{~cm}^{-1}$ therefore indicates a gas vesicle protein concentration of $0.0845 \mathrm{mg} \mathrm{ml}^{-1}$.

\section{The yield pressure of Microcystis gas vesicles}

Measurements of the yield pressure were made in four experiments on a suspension of Microcystis gas vesicles that initially had a critical pressure distribution similar to 
curve B in Fig. 2, with a median critical pressure $\left(p_{\mathrm{c}}\right)$ of $0.80 \mathrm{MPa}$, a mean $p_{\mathrm{c}}$ of $0.78 \mathrm{MPa}$, and a standard deviation of $0.15 \mathrm{MPa}$. In these four experiments an average of $82 \%$ of the gas vesicles remained intact in samples recovered from the pressure tube $A$ after the full cycle of gradual compression and decompression. It is assumed that the loss of gas vesicles occurred through collapse during the compression stages and that the weakest $18 \%$ of the gas vesicles had been lost; those that remained would therefore have had a mean $p_{\mathrm{c}}$ of 0.83 with standard deviation of $0.094 \mathrm{MPa}$. Fig. 5 shows the percentages of these remaining gas vesicles that withstand rapid decompression from different pressures. The graph indicates that $50 \%$ of the gas vesicles would have exploded when decompressed from a pressure of $4.3 \mathrm{MPa}$ ( 43 bar). This is the estimate of the median yield pressure, $p_{y}$, of the gas vesicles.

\section{Discussion}

The gas vesicles isolated from Microcystis have proved to be more stable than those of Anabaena: they remained more stable when stored, and were more stable when held under sustained pressures. The Microcystis gas vesicles therefore provide better material for a range of experiments. The gas vesicles that had been freshly isolated had a slightly higher mean critical pressure than those in the cells, probably because some of the weaker gas vesicles in the preparation were lost during centrifugation; the highest critical pressures were no higher than those of gas vesicles in the cells.

Inside cells, gas vesicles have to withstand sustained pressures generated by cell turgor and the hydrostatic head of water. Isolated gas vesicles that had been subjected to a pressure of $0.55 \mathrm{MPa}$ subsequently withstood a pressure of $0.5 \mathrm{MPa}$ without further collapse, but for those subjected to pressures closer to their critical pressure there appeared to be some dependence on the duration of the pressure. The cause of this is not known.

Because the gas vesicles isolated from Anabaena were more sensitive to this time-dependent collapse it was not possible to investigate their elastic compressibility at pressures approaching their critical pressures; at pressures up to $0 \cdot 1 \mathrm{MPa}$ the average compressibility was $0.0155 \mathrm{MPa}^{-1}$ and (in contravention of Hooke's law) it appeared to increase slightly with rising pressure (Walsby, 1982). More accurate measurements were made here with the Microcystis gas vesicles, which could be held without collapse at pressures up to $0.5 \mathrm{MPa}$; the compressibility, of $0.00871 \mathrm{MPa}^{-1}$, was perfectly linear up to this value. A lower compressibility is expected for the Microcystis gas vesicle because it is narrower and a given pressure therefore acts on a smaller cross-sectional area to develop a lower stress in the wall. A more useful comparison is made between the elastic properties of the wall material of the two types of gas vesicle.

The Young's modulus $(Y)$ of the wall of a cylindrical structure, like a gas vesicle, can be calculated from the (rearranged) equation of Newman \& Searle (1957)

$$
Y=K_{\mathrm{a}} r(4 \sigma-5) / 2 t
$$

For the Microcystis gas vesicle, $K_{\mathrm{a}}$, the elastic bulk modulus, is $115 \mathrm{MPa}$; $r$, the cylinder radius, is $32.6 \mathrm{~nm} ; t$, the mean wall thickness, is taken to be $1.8 \mathrm{~nm}$ (see Walsby \& Bleything, 1988); and $\sigma$, the Poisson ratio, $0 \cdot 33$ (see Walsby, 1982). Equation 5 then gives $Y=3.8 \mathrm{GPa}$. By substituting the appropriate values for the Anabaena gas vesicle of $K_{\mathrm{a}}=64.5 \mathrm{MPa}, \sigma=0.33$ (Walsby, 1982) $r=42 \mathrm{~nm}$ and $t=1.8 \mathrm{~nm}$ (Hayes et al., 1986), the value calculated for its wall material is $Y=2.8 \mathrm{GPa}$. This somewhat lower value must be related to the fact that the Anabaena gas vesicle became weaker when isolated from the cells.

When cyanobacterial gas vesicles collapse, the cylinders form rectangular flattened envelopes. The form of the collapsed structure indicates that the gas vesicle undergoes instability failure; the cylinder goes out-ofround and buckles so that breakage lines propagate parallel to the axis. In a cylinder of homogeneous wall structure the expected buckling pressure is given by

$$
p_{\mathrm{b}}=\left[Y t^{3}\left(q^{2}-1\right)\right] /\left[12\left(1-\sigma^{2}\right) t^{3}\right]
$$

where $Y, t, r$ and $\sigma$ have their previous meanings and $q$ is the number of half-waves in the buckled form (Allen \& Bulson, 1980). In a cylinder, like the gas vesicle, with an axial ratio of about $10, q=2$, whence $q^{2}-1=3$, and

$$
p_{\mathrm{b}}=\left[Y t^{3}\right] /\left[4\left(1-\sigma^{2}\right) t^{3}\right]
$$

(see Walsby, 1982). Substituting the values of $Y, t, r$ and $\sigma$ for the Microcystis gas vesicles gives $p_{\mathrm{b}}=0.18 \mathrm{MPa}$. This predicted buckling pressure is only 0.2 of the observed mean critical pressure $\left(p_{c}=0.882 \mathrm{MPa}\right.$ for the sample analysed); it confirms that the gas vesicle structure must be stiffened in such a way as to postpone buckling (Walsby, 1982). The theoretical buckling pressure is close to the decreased critical pressure of $0.23 \mathrm{MPa}$ that is observed when the outer covering of GVPc is removed from the Microcystis gas vesicle (Walsby \& Hayes, 1988). This suggests that GVPc provides the stiffening. It may do this by linking the ribs together (Walsby \& Hayes, 1988; Hayes et al., 1988).

The mean critical pressure of the Microcystis gas vesicles used in the explosion experiments, $p_{\mathrm{c}}=$ $0.83 \mathrm{MPa}$, was, in turn, only 0.2 of their yield pressure when the excess pressure was on the inside, $p_{y}=$ 4.3 MPa. This confirms that, although buckling is postponed, instability failure under excess external pressure occurs well before the yield pressure is reached. 
An estimate of the yield stress of the proteinaceous gas vesicle wall can be obtained from the value of $p_{y}$. An excess pressure $\left(p_{i}\right)$ inside a cylinder generates a longitudinal stress $\left(s_{1}\right)$ in the wall, running parallel to the principal axis, equal to $p_{\mathrm{i}} r / 2 t$. For reasons of geometry the transverse stress $\left(s_{t}\right)$, at right angles to the cylinder axis, is twice this, $p_{\mathrm{i}} r / t$. Failure of the cylinder, therefore, occurs when the transverse stress reaches the yield stress of the wall material, when

$$
s_{\mathrm{y}}=p_{\mathrm{y}} r / t
$$

Substituting the values given above for the Microcystis gas vesicles, it is calculated that $s_{y}=78 \mathrm{MPa}$. It is interesting to compare the mechanical properties of the gas vesicle wall material with those of synthetic polymers that have been investigated in bulk quantities. The principal protein of the gas vesicle wall, GVPa, is largely in the form of $\beta$-sheet in which $\beta$-chains of peptides, -[CO-NH-CHR], are hydrogen-bonded to adjacent chains (Blaurock \& Walsby, 1976; see Fig. 6 of Walsby \& Hayes, 1989). The most apt comparison is with the polymer nylon, which has an analogous structure with $\beta$ chains of $-\left[\mathrm{CO}-\mathrm{NH}-\left(\mathrm{CH}_{2}\right)_{n}\right]-$ hydrogen-bonded in a similar way. The Young's modulus of dense nylon is within the range 2 to $4 \mathrm{MPa}$ and its yield stress is $83 \mathrm{MPa}$ (Ashby \& Jones, 1980). These values are very close to those determined here for the gas vesicle protein. The agreement indicates that the mechanics developed by engineers for the understanding of large structures can be used for the understanding of biological structures with molecular dimensions.

This work was supported by grants from the SERC and NERC. I wish to thank Annette Bees for culturing the cyanobacteria and $\operatorname{Dr} A$. Blakeborough for discussions on mechanics.

\section{References}

AlLeN, H. G. \& Bulson, P. S. (1980). Background to Buckling. London: McGraw-Hill.

AsHBY, M. F. \& JonES, D. R. H. (1980). Engineering Materials. An Introduction to their Properties and Applications. Oxford: Pergamon Press.

Blaurock, A. E. \& WalsBY, A. E. (1976). Crystalline structure of the gas vesicle wall from Anabaena flos-aquae. Journal of Molecular Biology 105, 183-199.

Damerval, T., Houmard, J., Guglielmi, G., Csiszàr, K. \& Tandeau DE MARSAC, N. (1987). A developmentally regulated gvp $A B C$ operon is involved in the formation of gas vesicles in the cyanobacterium Calothrix 7601. Gene 54, 83-92.

Damerval, T., Castets, A.-M., Guglielmi, G. Houmard, J. \& TANDEAU DE MARSAC, N. (1989). Occurrence and distribution of gas vesicle genes among cyanobacteria. Journal of Bacteriology 171, 1445-1452.

DeHART, R. C. (1969). External-pressure structures. In Handbook of Ocean and Underwater Engineering, pp. 9-3 to 9-20. Edited by J. J. Myers, C. H. Holm \& R. F. McAllister. New York: McGraw-Hill.
HAYES, P. K. (1988). Gas vesicles: chemical and physical properties. Methods in Enzymology 167, 213-222.

HAYES, P. K. \& WALSBY, A. E. (1986). The inverse correlation between width and strength of gas vesicles in cyanobacteria. British Phycological Journal 21, 191-197.

HAYES, P. K., WAlsby, A. E. \& Walker, J. E. (1986). Complete amino acid sequence of cyanobacterial gas-vesicle protein indicates a 70residue molecule that corresponds in size to the crystallographic unit cell. Biochemical Journal 236, 31-36.

Hayes, P. K., Lazarus, C. M., Bees, A., Walker, J. E. \& Walsby, A. E. (1988). The protein encoded by $g v p C$ is a minor component of gas vesicles isolated from the cyanobacteria Anabaena flos-aquae and Microcystis sp. Molecular Microbiology 2, 545-552.

Hemmingsen, B. B. \& Hemmingsen, E. A. (1980). Rupture of the cell envelope by induced intracellular gas phase expansion in gas vacuolate bacteria. Journal of Bacteriology 143, 841-846.

Hodgman, C. D. (editor-in-chief) (1963). Handbook of Chemistry and Physics. Cleveland, Ohio: Chemical Rubber Publishing Company.

Newman, F. H. \& Searle, V. H. L. (1957). The General Properties of Matter. London: Edward Arnold.

OLIVER, R. L. \& WALSBY, A. E. (1988). Buoyancy and suspension of planktonic cyanobacteria. Methods in Enzymology 167, 521-527.

Rippka, R., Deruelles, J., Waterbury, J. B., Herdman, M. \& Stanier, R. Y. (1979). Generic assignments, strain histories and properties of pure culture of cyanobacteria. Journal of General Microbiology 111, 1-61.

Tandeau de Marsac, N., Mazel, D., Bryant, D. A. \& Houmard, J. (1985). Molecular cloning and nucleotide sequence of a developmentally regulated gene from the cyanobacterium Calothrix PCC 7601: a gas vesicle protein gene. Nucleic Acids Research 13, 7223-7236.

WALKER, J. E., HAYEs, P. K. \& WALSBY, A. E. (1984). Homology of gas vesicle proteins in cyanobacteria and halobacteria. Journal of General Microbiology 130, 2709-2715.

WALSBY, A. E. (1969). The permeability of blue-green algal gas-vacuole membranes to gas. Proceedings of the Royal Society B173, 235-255.

WALSBY, A. E. (1971). The pressure relationships of gas vacuoles. Proceedings of the Royal Society B178, 301-326.

WALSBY, A. E. (1972). Structure and function of gas vacuoles. Bacteriological Reviews 36, 1-32.

WALSBY, A. E. (1973). A portable apparatus for measuring relative gas vacuolation, the strength of gas vacuoles, and turgor pressure in planktonic blue-green algae and bacteria. Limnology and Oceanography 18, 653-658.

WALSBY, A. E. (1974). The isolation of gas vesicles from blue-green algae. Methods in Enzymology 31A, 678-686.

WALSBY, A. E. (1978). The properties and buoyancy-providing role of gas vacuoles in Trichodesmium Ehrenberg. British Phycological Journal 13, 103-116.

WALSBY, A. E. (1980). The water relations of gas-vacuolate prokaryotes. Proceedings of the Royal Society B208, 73-102.

WALSBY, A. E. (1982). The elastic compressibility of gas vesicles. Proceedings of the Royal Society B216, 355-368.

WALSBY, A. E. (1984). Lower limit of the gas permeability coefficient of gas vesicles. Proceedings of the Royal Society B223, 177-196.

WALSBY, A. E. (1987). Mechanisms of buoyancy regulation by planktonic cyanobacteria with gas vesicles. In The Cyanobacteria, pp. 377-392. Edited by P. Fay \& C. Van Baalen. Amsterdam: Elsevier.

WALSBY, A. E. (1989). The gas vesicle: a stable gas-filled structure in bacteria. In Supersaturation and Bubble Formation in Fluids and Organisms, pp. 69-103. Edited by A. O. Brubakk, B. B. Hemmingsen \& G. Sundnes. Trondheim, Norway: Tapir Publishers.

WalsBy, A. E. \& BleYthing, A. (1988). The dimensions of cyanobacterial gas vesicles in relation to their efficiency in providing buoyancy and withstanding pressure. Journal of General Microbiology 134, 2635-2645.

WALSBY, A. E. \& HAYES, P. K. (1988). The minor cyanobacterial gas vesicle protein GVPc, is attached to the outer surface of the gas vesicle. Journal of General Microbiology 134, 2647-2657.

WALSBY, A. E. \& HAYES, P. K. (1989). Gas vesicle proteins. Biochemical Journal 264, 313-322. 